\title{
Overview of Immunoelectron Microscopy
}

\author{
Chang-Hyun Park*, Hong Lim Kim ${ }^{1}$, Byung-Joon Chang ${ }^{2}$, Sang Hoon Lee ${ }^{3}$, Byung Soo Chang ${ }^{4}$, \\ Chun-Sik Bae ${ }^{5}$, Ik-Hyun $\mathrm{Cho}^{6}$, Dong Heui Kim ${ }^{7}$, Jung-Mi Han ${ }^{2}$, Ji Eun $\mathrm{Na}^{8}$, Byung-Jin Choi, \\ Sang-Sik Kim, Hyun-Wook Kim, Jee-Woong Kim ${ }^{9}$, Im Joo Rhyu ${ }^{8}$, Chang-Sub Uhm ${ }^{8}$ \\ Medical Science Research Center, Korea University College of Medicine, Seoul 02841, Korea \\ ${ }^{1}$ Integrative Research Support Center, The Catholic University of Korea, Seoul 06591, Korea \\ ${ }^{2}$ College of Veterinary Medicine, Konkuk University, Seoul 05029, Korea \\ ${ }^{3}$ Korea Brain Research Institute, Daegu 41062, Korea \\ ${ }^{4}$ Department of Cosmetology, Hanseo University, Seosan 31962, Korea \\ ${ }^{5}$ College of Veterinary Medicine, Chonnam National University, Gwangju 61186, Korea \\ ${ }^{6}$ Department of Convergence Medical Science, College of Korean Medicine, Kyung Hee University, Seoul 02447, Korea \\ ${ }^{7}$ Department of Environmental Medical Biology, Yonsei University Wonju College of Medicine, Wonju 26426, Korea \\ ${ }^{8}$ Department of Anatomy, Korea University College of Medicine, Seoul 02841, Korea \\ ${ }^{9}$ Division of Biosafety Evaluation and Control, Korea National Institute of Health, Cheongju 28159, Korea
}

*Correspondence to:

Park $\mathrm{CH}$,

(iD) http://orcid.org/0000-0002-7306-035X

Tel: $+82-2-2286-1323$

Fax: +82-2-2286-1329

E-mail: kmemno1@empal.com

Received July 24, 2018

Revised November 5, 2018

Accepted November 11, 2018
Immunoelectron microscopy using an antigen-antibody reaction in an electron microscope is a very useful tool to identify the components of a tissue in an electron microscope. Many researchers also use immunoelectron microscopy. Nonetheless, immunoelectron microscopy is rarely introduced systematically, and immunoelectron microscopy can be carried out without fully understanding the principles, and cases of poor understanding can often be seen in the vicinity. Therefore, in order to make it easier to understand, we will first introduce the principles of immunoelectron microscopy and describe practical methods.

Key Words: Pre-embedding, Post-embedding, Immuno cytochemistry, Correlative light and electron microscopy

\section{INTRODUCTION}

Immunoelectron microscopy is a method of performing an immunohistochemical method using an optical microscope in an electron microscope, and is called various name such as immunocytochemistry and electron microscopic immunohistochemistry.

Immunocytochemistry is a method of screening components in a tissue using an antigen-antibody reaction. An antibody is a protein, carbohydrate, or lipid molecule that is recognized as a foreign substance to an individual, and is generally a polymer having a molecular weight of 10,000 or more. One antigen has one or several antibody binding sites, which are present in a localized region consisting of a very specific small number of amino acids or polysaccharides. Antibodies will be described in more detail below.

\section{PRINCIPLE OF IMIMUNOCYTOCHEMISTRY}

\section{Types and Characteristics of Antibodies}

Immunoglobulins are the result of humoral immune responses. IgE, IgA, IgM, IgD, and IgG are classified according to the order of the amounts present in the serum. IgG and IgM are mainly used for immunohistochemical staining, and two heavy chains and two light chains form a Y-shaped complex (Fig. 1).

In the case of papain (blue line in Fig. 1) treatment: 2 Fab+Fc, pepsin (red line in Fig. 1) treatment. F(ab')2+Fc. Fab frag-

@ This is an open-access article distributed under the terms of the Creative Commons Attribution Non-Commercial License (http://creativecommons.org/licenses/by-nc/4.0) which permits unrestricted noncommercial use, distribution, and reproduction in any medium, provided the original work is properly cited.

Copyrights @ 2018 by Korean Society of Microscopy 


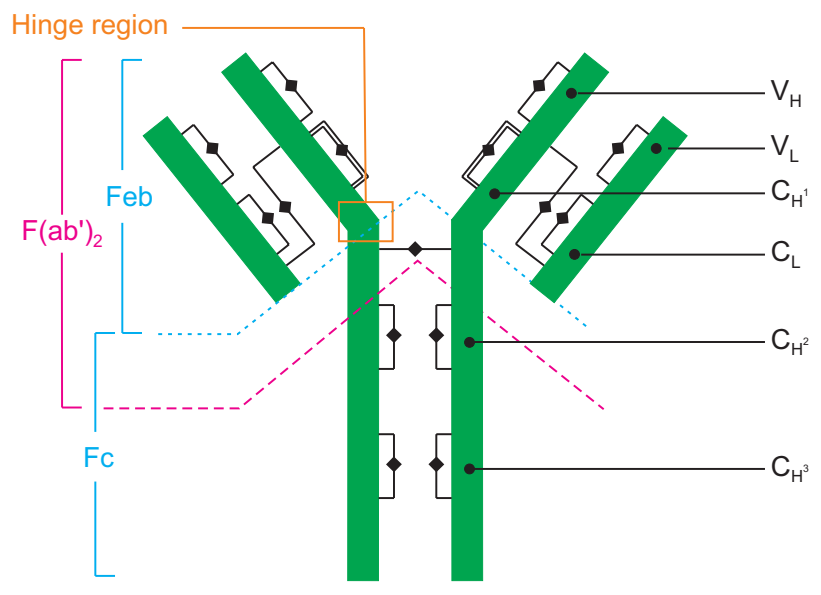

Fig. 1. Structure of the immunoglobulin G molecule.

ments are smaller than whole $\operatorname{IgG}$ and are used to find antigens that are deep inside cells.

IgM is used in the absence of IgG antibody because 5 structures such as IgG have a pentagonal shape and are very large in size compared to IgG.

For example, when serum is used as a primary antibody, IgM is used at the initial stage of infection where only IgM is present before IgG is generated.

\section{Classification of Antibodies}

The monoclonal antibody is composed of an antibody that is separated from the culture fluid or ascites of the hybridoma cell line that fused myeloma cells with the B cell that secretes the specific antibody that is separated from the mouse spleen and reacts with a specific epitope of the antigen.

Because it contains pure antibody that reacts only to specific antigen, it is less specific reaction, easy to characterize, and same antibody can always be obtained in same hybridoma cell line. Depending on the test method, a false negative reaction that does not show a response may appear.

For example, if you are stained with western blot, but are not stained with tissue, or if you buy anti-monoclonal antibodies, you may want to purchase with consideration of the method you use, or purchase and test several different types of monoclonal antibodies.

Polyclonal antibodies are usually immunoglobulins isolated from rabbit serum or serum. Rabbits are relatively easy to breed, and there is little chance of a cross-reaction because there are few human antibodies to rabbit serum. Regardless of the time of collection of serum, it contains a certain amount of antibody. It reacts with various kinds of antigens and shows excellent results in immunohistochemical staining for tissues. Antigen-antibody reactions occur well even in high-antigen or high-antibody conditions.

\section{Antibody Stability}

For monoclonal antibodies, whole serum is more stable than unfrozen purified immunoglobulin. This is because the $\mathrm{pH}$ or salt change and hydrophobicity used during the purification process cause the antibody to aggregate. Polyclonal antibodies IgM and IgG2 are particularly sensitive to specificity, affinity, and cross-reactivity. To safely store the antibody, aliquot it and store it at $-20^{\circ} \mathrm{C}$ or less regardless of the type of antibody.

\section{Antibody Handling Precautions}

Handling and storage of antibodies is very important for proper immunostaining. The antibody should be stored and handled according to instructions as soon as it arrives. The general precautions for storage should be as follows: First, use a container with low protein absorptivity such as polypropylene, polycarbonate, borosilicate glass, etc. Second, if the concentration of the protein is lower than $1 \sim 10 \mathrm{mg}, 0.1 \% \sim 1.0 \%$ bovine serum albumin (BSA) is added to prevent polymerization or absorption in a storage container. Third, the stock solution should be aliquot and stored at $-20^{\circ} \mathrm{C}$ or lower. The diluted solution should be kept in the refrigerator.

\section{Antigen-antibody Response}

The affinity of the antibody for the antigen is determined by the structure of the variable region of the antibody. Second, the binding between the protein antigen and the antibody depends on the electrostatic force (Coulomb's law), and the binding between the polyglyc antigen and the antibody is van der Waals force or dispersion force. In addition, it is influenced by ionic bond and hydrogen bond, and hydrophobic interaction stabilizes antigen-antibody complex (however, covalent bond is not involved).

$$
\begin{gathered}
\text { F coulombic }=\frac{Q^{+} \cdot Q^{-}}{\varepsilon \delta^{2}} \\
Q^{+}, Q^{-}: \text {Charge, } \delta^{2}: \text { distance of protons } \\
\text { F dispersion }=\frac{A \cdot a}{\delta^{7}}
\end{gathered}
$$

\section{A: fixed number of antigen, a: fixed number of antigen size}

Functional affinity is the time it takes for an antigen and an antibody to react with each other to an equilibrium state, and the antigen-antibody reaction is a reversible reaction, and the binding can be broken during the washing process. Since monoclonal antibodies have only one affinity antibody, care must be taken to avoid degradation of antigen-antibody conjugates due to high salt concentration, high temperature, and low $\mathrm{pH}$. In the case of polyclonal antibodies, since they have a mixture of antibodies with various affinities, it is often not necessary to pay attention to monoclonal antibodies.

Cross reactivity refers to the case where an antibody reacts 
with several antigenic epitopes or vice versa. There is an incidental change in the experiment or by the antigen retrieval process, a reaction with a similar epitope of an antigen of no relevance, or a species cross reactivity of another species that is the same or similar to a human antigen. Cross reactivity does not refer to the same antigen present in other tissues or cells.

The reaction rate is usually 48 hours, but depends on the tissue fixation state, antibody concentration, reaction temperature and other requirements. High affinity antibody can be used at high concentration to reduce the reaction time. If the concentration increases 2 to 3 times, the reaction time may be reduced from 30 minutes to 90 seconds. However, the nonspecific background staining is disadvantageous in this case. If the antibody is used at low concentration for a long time, it can be cleanly stained without background staining and repeatedly using the same antibody.

Antibody tite and dilution are also important. Antibody refers to the maximum dilution of an antibody capable of optimal staining with minimal background. The monoclonal antibody is diluted 1:5 to $1: 1,000$ (culture supernatants) or 1:1,000,000 (ascitic fluids), and the polyclonal antibody is diluted to 1:100 to 1:2,000. Dilution of the antibody should be performed after titration to determine the optimal dilution, and finally diluted using a 1:10 pre-diluted stock.

Reaction time and temperature depend on antibody incubation. First, the reaction time is inversely related to the concentration of the antibody. It is convenient to determine the concentration (dilution ratio) of the antibody after determining the reaction time. Generally at least 20 minutes (up to 48 hours). Second, the higher the reaction temperature, the faster the equilibrium is reached. React at $37^{\circ} \mathrm{C}$ (be careful to keep the humidity) or at $4^{\circ} \mathrm{C}$ (overnight incubation). Third, control settings should also be considered. Control settings include reagent control and tissue control. The reagent control is most important for the control of the primary antibody. Positive controls use affinity-absorbed antiserum or homologous immunoglobulin. Negative controls use non-immune rabbit serum or immunoglobulin for polyclonal antibodies. For example, when 832 parts of buffer are mixed with nonimmune rabbit serum 1 part, the final protein concentration is $0.024 \mathrm{~g} / \mathrm{L}(2.4 \mathrm{mg} / \mathrm{L})$.

Positive control in Tissue control is used in tissues where the antigen is definitely present, negative controls are used in tissues in which no antigen is definitely present, and internal controls are used in comparison to other tissues obtained from the same species.

The process of visualization of the reaction is also necessary. A. At the optical microscope level, enzymes such as Horseradish peroxidase (HRP), alkaline phosphatase (AP) and glucose oxidase are used to color reaction products. In order to amplify the reaction, a method of using a bridge such as PAP,
$\mathrm{ABC}$ or $\mathrm{B}-\mathrm{SA}$ is often used. In addition, fluorescent materials and radioactive isotopes are often used. B. At the electron microscopic level, 3,3'-diaminobenzidine (DAB) enzyme is used as substrate for HRP, or heavy metals such as ferritin and gold are labeled.

\section{Immunostaining Method}

In optical microscopy, multistage staining method is used to increase the sensitivity of staining, but in electron microscope, simple method is preferred.

The direct method involves reacting the primary antibody with a marker (ferritin, gold) and observing it immediately without further manipulation. It is used when there is a sufficient number of primary antibodies, and it is possible to identify the precise localization of intracellular antigens. It is difficult to observe when the amount of antigen is small.

Indirect method is a method of reacting primary antibody with antigen and finding primary antibody with secondary antibody attached to the marker. It is suitable for multiple staining, and the location of the intracellular antigen may be somewhat different, but it is easy to confirm by the amplification of the signal.

Immunostaining is the easiest way to attach a marker, such as gold, to a primary antibody. If the amount of antigen is small, the signal can be amplified about 10 times by indirect method. The most commonly used methods are the indirect method, in which gold is added to the secondary antibody, or the three-step indirect method, in which the third antibody is used in the absence of the antibody.

\section{Marker: Colloidal Gold}

Recently, a method commonly used in immunoelectron microscopy is a method of labeling an antigen with an HRPtagged antibody, reacting DAB with a substrate to produce an electron dense reaction product, and labeling using a colloidal gold or immuno-gold.

The advantages of colloidal gold are: a. There are various sizes of gold particles. b. It is easily observed with an electron microscope. c. It can be used at both optical and electron microscopic levels.

Selection of antibodies: a. In principle, the use of secondary antibodies is the most specific. b. If there is no or more secondary antibody, use protein A, G, or A/G. All bind to the single binding site of the Fc part of the primary antibody. The secondary antibody amplifies the signal from the protein A, G. Can be used for various antibodies regardless of type (Table 1). The size of the gold particles to be used in the immune response should be appropriately selected. The smaller the gold particle size, the higher the labeling intensity. In principle, gold particles of any size can be used (Table 2). 
Table 1. Relative affinity of protein A, G, and A/G

\begin{tabular}{|c|c|c|c|c|}
\hline \multicolumn{2}{|c|}{ Primary antibody } & \multirow{2}{*}{$\begin{array}{c}\begin{array}{c}\text { Protein } \\
\text { A gold }\end{array} \\
+++\end{array}$} & \multirow{2}{*}{$\begin{array}{c}\begin{array}{c}\text { Protein } \\
\text { C gold }\end{array} \\
+++\end{array}$} & \multirow{2}{*}{$\begin{array}{c}\begin{array}{c}\text { Protein } \\
\text { A/G gold }\end{array} \\
+++\end{array}$} \\
\hline Rabbit & IgG & & & \\
\hline \multirow[t]{3}{*}{ Mouse } & IgG & ++ & ++ & ++ \\
\hline & $\operatorname{IgM}$ & $+/-$ & $+1-$ & $+/-$ \\
\hline & IgA & $+/-$ & $+/-$ & $+/-$ \\
\hline Rat & IgG & $+/-$ & + & +++ \\
\hline \multirow[t]{6}{*}{ Human } & IgG1 & +++ & +++ & +++ \\
\hline & IgG2 & +++ & +++ & +++ \\
\hline & IgG3 & $+/-$ & +++ & +++ \\
\hline & IgG4 & +++ & +++ & +++ \\
\hline & $\operatorname{IgM}$ & + & - & - \\
\hline & IgA & + & - & - \\
\hline Guinea pig & IgG & ++ & ++ & ++ \\
\hline Goat & IgG & $+/-$ & ++ & +++ \\
\hline Bovine & IgG & ++ & ++ & ++ \\
\hline Sheep & IgG & $+/-$ & ++ & +++ \\
\hline Chicken & IgG & $+/-$ & + & $+/-$ \\
\hline
\end{tabular}

Ig, immunoglobulin.

Table 2. Selection of gold particles according to observation method

\begin{tabular}{|c|c|c|}
\hline Condition & $\begin{array}{l}\text { Gold particle } \\
\text { size }(\mathrm{nm})\end{array}$ & Remarks \\
\hline \multicolumn{3}{|l|}{ TEM } \\
\hline Low magnification & $15 \sim 30$ & \\
\hline High magnification & $5 \sim 10$ & $\begin{array}{l}10 \mathrm{~nm} \text { particles are most } \\
\text { commonly used } \\
\text { Silver enhancement if needed }\end{array}$ \\
\hline $\begin{array}{l}\text { Ultra-sensitive } \\
\text { labeling }\end{array}$ & 1 & Silver enhancement required \\
\hline $\begin{array}{l}\text { Pre-embedding } \\
\text { labeling }\end{array}$ & 1 & Silver enhancement required \\
\hline \multirow[t]{2}{*}{ SEM } & $20 \sim 30$ & Unenhanced observation \\
\hline & 5 & Enhanced observation \\
\hline
\end{tabular}

\section{Precautions for Sample Handling for Immunostaining}

First, fixation should be appropriate to preserve tissue microstructure and maintain antigenicity. The basic conditions are: a. Maintain good morphological preservation, b. Do not destroy immunogenicity of antigen, c. Prevent extraction of antigens from processing such as fixing and dehydration, $\mathrm{d}$. and do not interfere with antigen-antibody reaction.

The conditions may vary from one organization to another, but efforts should be made to select the way in which the antigen to be observed is conserved (Table 3 ).

Glutaraldehyde is good in shape retention, but has limited penetration and is not used because the retention of antigenic epitope is very poor. Paraformaldehyde may be used alone or in combination with $0.1 \%$ to $0.2 \%$ glutaraldehyde. Old paraformaldehyde can damage antigenicity, so always use fresh fixative. Glutaraldehyde is used for preservation of mi-
Table 3. Characteristics of fixative

\begin{tabular}{lccc}
\hline $\begin{array}{c}\text { Type of } \\
\text { fixative }\end{array}$ & $\begin{array}{c}\text { Structure } \\
\text { preservation }\end{array}$ & $\begin{array}{c}\text { Antigenic } \\
\text { preservation }\end{array}$ & $\begin{array}{c}\text { Application } \\
\text { field }\end{array}$ \\
\hline $\begin{array}{l}\text { Coagulative (cross linking) } \\
\text { Formaldehyde }\end{array}$ & ++ & ++ & Tissues \\
Glutaraldehyde & +++ & + & Tissues \\
Additive (precipitating) & & & \\
Acetone & + & + & Cells \\
Methanol & + & + & Cells \\
Mixed & & & \\
Formal acetone & ++ & + & Cells \\
Picric acid & ++ & & Tissues \\
\hline
\end{tabular}

crostructure. The following is an example of the mixing ratio of the fixative used for immunostaining- $0.2 \mathrm{M}$ phosphate buffer (PB) (pH 7.4; $50 \mathrm{~mL} ; 8 \%$ (w/v) paraformaldehyde, 25 $\mathrm{mL} ; 25 \%(\mathrm{w} / \mathrm{v})$ paraformaldehyde, $0.8 \mathrm{~mL}$; distilled water, $24.2 \mathrm{~mL}$.

Osmium should not be used because the preservation of antigenicity is very bad.

The utility of the antigen retrieval technique for antigenicity recovery has not been verified. However, there is a need for an unmasking process that exposes the antigenic site. A sample immobilized on the Aldehyde system fixative is masked by the immobilization of the antigen and the function of the antigen is reduced. If necessary, the proteolytic enzyme is used to restore the function of the antigen, and the cross-linking degree varies depending on the fixed time, so that the enzyme treatment time is prolonged when the fixing time is long. Note that enzyme digestion under unfavorable conditions (concentration, temperature, time) may damage some of the antigens that are desired. Commonly used enzymes include trypsin, pepsin, and protease.

Second, the washing process is important, and perfect washing is a prerequisite for successful immunostaining. The background labeling can be reduced by completely eliminating excessive aldehyde. If the washing time is reduced, the aldehyde group is neutralized using ammonium chloride or 0.05 to 0.1 M glycine (in phosphate-buffered saline [PBS]). After fixation, wash with buffer having the most similar tonicity to normal tissues. Washing time should be at least equal to fixed time. To prevent the formation of antigen-antibody complexes that form precipitates in immunostaining sections or to prevent background staining, which is a problem of reading, a suitable buffer (Tris-buffered saline [TBS], cacodylate buffer, PB, etc.) should be used for washing.

Third, consider blocking. Endogenous enzymes can cause false positive reactions when enzymes such as those used to visualize antigen-antibody reactions in tissues are present (often seen in red blood cells, white blood cells, tumor tissue, etc.). Peroxidase: Add $0.3 \%$ hydrogen peroxide to absolute methanol for 10 to 30 minutes at room temperature. Add AP: 
$1 \mathrm{mM}$ levamisole to the final incubation media. However, $20 \%$ acetic acid or $0.3 \% \mathrm{H}_{2} \mathrm{O}$ or $2.5 \%$ peroxidase should be used in the intestine. Other enzymes are not a problem.

In the background stain, specific background stain is rarely a problem, but it can be caused by plasma proteins in tissues with inflammatory products or necrosis, or in an inadequate or long time immobilized tissue. Elimination of this background stain prevents anti-albumin or fast and fast fixation. The nonspecific background stain is the main cause of nonimmunological binding of electrostatic forces and hydrophobic specific immune serum to certain sites in the section. These background stain removal methods treat immunoglobin that does not react with the primary specific antiserum, but does not interfere with it, or a complete normal serum. The primary antisera can be reduced by the use of Tris buffer with a detergent additive such as triton $\mathrm{X}$, or by the addition of $2.5 \% \mathrm{NaCl}$ to the buffer. Enzymatic digestion can reduce nonspecific background stain.

Fourth, consider incubation and dilution. The buffer used for antigen dilution and reaction is generally adjusted to $\mathrm{pH} 8.2$ by mixing normal goat serum (1\%), Tween $20(0.2 \%$ or saponin) and BSA (1\%) in PBS or TBS. Note that when using protein $A, G$, or $A / G$, the use of normal goat serum should not be used. Second, when selecting a serum, use a gold particle as the host species of the antibody.

The procedure for Pre-embedding is given below (Fig. 2):

1. Fixation

- $4 \%$ paraformaldehyde $+0.1 \%$ glutaraldehyde

2. Permeabilization

$-0.1 \%$ saponin/PBS 3 hours at room temperature

3. Immuno-labeling

- Primary antibody:
- Secondary antibody: gold-conjugated (1 2 $\mathrm{nm})$ protein A (silver enhancement - HQ Silver ${ }^{\mathrm{TM}}$ [Nanoprobes] 10 minutes room temperature)

4. Refixation \& osmication

5. Processing for routine electron microscopy (EM) (dehydration, embedding, sectioning, staining)

6. Observation

The procedure for post-embedding is given below (Fig. 2):

1. Fixation

- $4 \%$ paraformaldehyde $+0.1 \%$ glutaraldehyde

2. Processing for routine EM (dehydration, embedding)

3. Sectioning

4. Immuno-labeling

- Primary antibody:

- Secondary antibody: gold-conjugated (10 20 nm)

protein A

5. Staining

6. Observation

\section{TECHNIQUE OF IMMUNOELECTON MICROSCOPY}
Immuno-Scanning Electron Microscope Protocol
1. Washing (PBS)
2. Fixation (4\% paraformaldehyde)
3. Washing (PBS, room temperature [RT], 15 minutes $\times 3$ )
4. Primary antibody incubation (RT, 1 hour or $4^{\circ} \mathrm{C}$ over- night, 1:500 dilution in 1\% BSA, PBS)
5. Washing (PBS)
6. Secondary antibody incubation (RT, 1 hour, 1:50 dilution in $1 \% \mathrm{BSA}, \mathrm{PBS}$ )
7. Washing (PBS, RT, 15 minutes $\times 3$ )

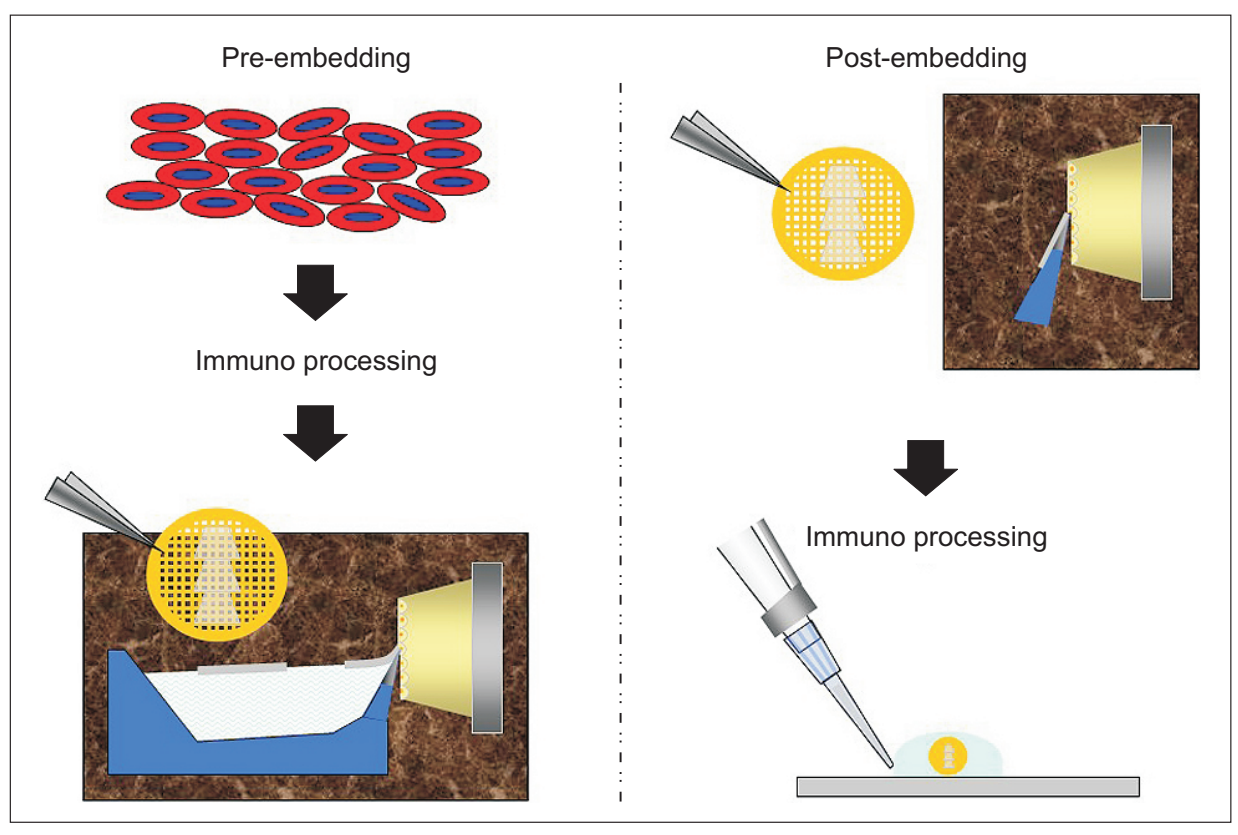

Fig. 2. Comparison of pre-embedding and post-embedding. 
8. Fixation $\left(2.5 \%\right.$ glutaraldehyde, $4^{\circ} \mathrm{C}, 1$ hour $)$

9. Washing (PBS, RT, 15 minutes $\times 3$ )

10. Osmication $\left(1 \%, 4^{\circ} \mathrm{C}, 1\right.$ hour $)$

11. Dehydration

12. Drying

13. Carbon coating (lightly)

14. Observation (Fig. 3; Goldberg, 2016)

\section{Pre-embedding Method (Melo et al., 2014)}

Immuno-gold (Nanogold ${ }^{\circledR}$ ) staining using the vibratome sections

1. Fix specimens with $4 \%$ paraformaldehyde in $0.1 \mathrm{M} \mathrm{PB}$ for 3 hours

2. Wash with $0.1 \mathrm{M}$ PB 3 times

3. Specimen sections into $50 \mu \mathrm{m}$ thickness with vibratome.

4. Blocking the sections with $1 \%$ BSA in $0.01 \mathrm{M}$ PBS for 1 hour.

5. Incubate at $4^{\circ} \mathrm{C}$ overnight with primary antibody within dilution range in $0.01 \mathrm{M}$ PBS.

6. Wash specimens 3 times in 0.01 M PBS, 10 minutes per wash.

7. Incubate 3 hours at room temperature with $1.4 \mathrm{~nm}$ goldlabeled secondary antibody (Nanogold ${ }^{\circledR}$, Nanoprobes) in $0.01 \mathrm{M}$ PBS.

8. Repeat the step 6 and then followed by washing in $0.1 \mathrm{M}$ PB 3 times for 10 minutes each time.

9. Fix with $1 \%$ glutaraldehyde in $0.1 \mathrm{M}$ PB for 30 minutes, $\mathrm{pH} 7.4$.

10. Wash the specimen sectioned in $0.1 \mathrm{M} \mathrm{PB} 3$ times for 10 minutes each

11. Post-fixation with $1 \%$ osmium tetroxide $\left(\mathrm{OsO}_{4}\right)$ in $0.1 \mathrm{M}$ $\mathrm{PB}$ for 10 minutes.

12. Wash in $0.1 \mathrm{M}$ PB 3 times for 10 minutes each.

13. Wash in double-distilled water 3 times.

14. Enhance using Silver enhancement mixture (HQ Silver ${ }^{\mathrm{TM}}$ ) prepared by mixing a 1:1:1 of initiator, moderator and activator in the darkroom for 3 5 minutes.

15. Wash in double-distilled water 3 times.

16. Dehydrate in a graded series of ethanol (50\%, 70\%, 80\%, $90 \%, 95 \%, 100 \% \times 3)$ and pure acetone for 10 minutes each

17. Embed in resin infiltration by ascending concentration of resin (acetone/resin 2:1, 1:1, 1:2, and pure resin $\times 2$ ).

18. Mount the sections between two thin plastic films for being flat.

19. Polymerize it in a $60^{\circ} \mathrm{C}$ oven for 36 hours.

20. Separation polymerized sections from plastic films and gluing to the epon block.

21. Proceed with cutting ultrathin section ( $80 \mathrm{~nm}$ thick) with microtome.

22. Stain with $2 \%$ uranyl acetate for 10 minutes.

23. Examine in the electron microscope (Fig. 4, 5).

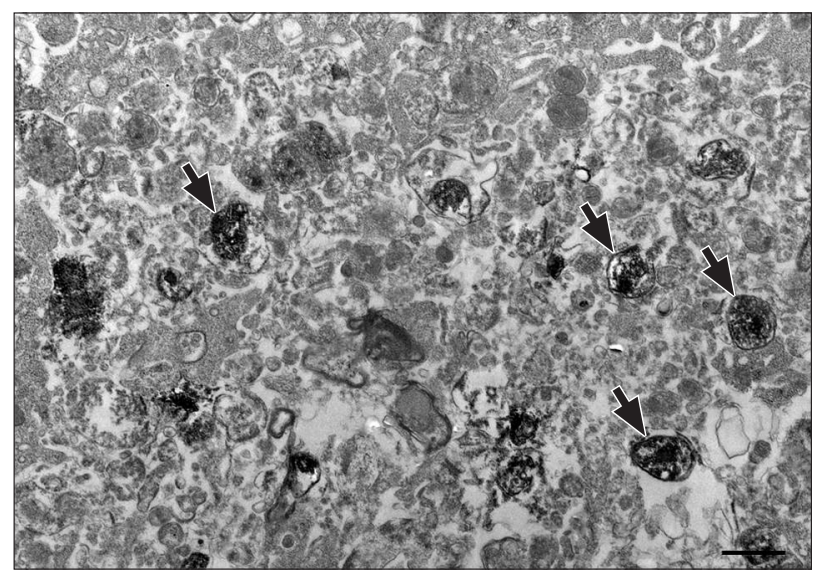

Fig. 4. Electron micrographs showing osteopontin-labeled mitochondria (arrows) using immunoperoxidase electron microscopy in the 3-nitropropionic acid-injured lesion core in rat brain. Scale bar $=1 \mu \mathrm{m}$.
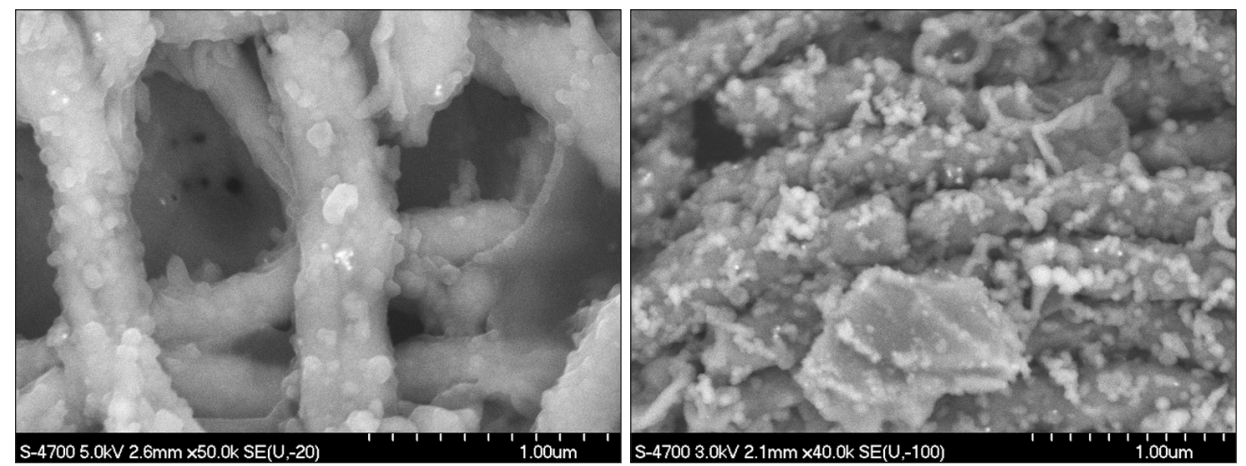

Fig. 3. Immunolabelling was performed with a primary antibody: Chemicon MAB922 \& secondary antibody: Gold-conjugated (15 nm) protein A (supplied by Prof. Su Jin Kim), and then refinement \& osmication and routine processing for scanning electron microscope (SEM), freeze drying and observed by field emission SEM (S-4700; Hitachi). The white spots in the picture are $15 \mathrm{~nm}$ gold. In the transmission electron microscope, the gold particles appear black because they interfere with the transmission of electrons (Goldberg, 2016). 


\section{Post-embedding Method}

1. Fixation with $4 \%$ paraformaldehyde, $0.2 \%$ glutaraldehyde in $0.1 \mathrm{M} \mathrm{PB}$

2. Washing with $0.1 \mathrm{M} \mathrm{PB} 10$ minutes 3 times

3. Dehydration with ethanol 30\%, 50\%, 70\%, 90\%, 100\% each 2 minutes

4. Infiltration

- 50\% ethanol, 50\% LR gold monomer mixture 30 minutes
- 30\% ethanol, 70\% LR gold monomer mixture 1 hour - 100\% LR gold monomer 1 hour

5. Embedded with LR gold resin and polymerization with UV light at $25^{\circ} \mathrm{C}, 24$ hours

6. Section with ultramicrotome $60 \sim 70 \mathrm{~nm}$ on formvar coated nickel grid.

7. Immunization

- PBS-milk-Tween (0.1\% PBS, $0.2 \%$ milk, $0.1 \%$ Tween 20$)$
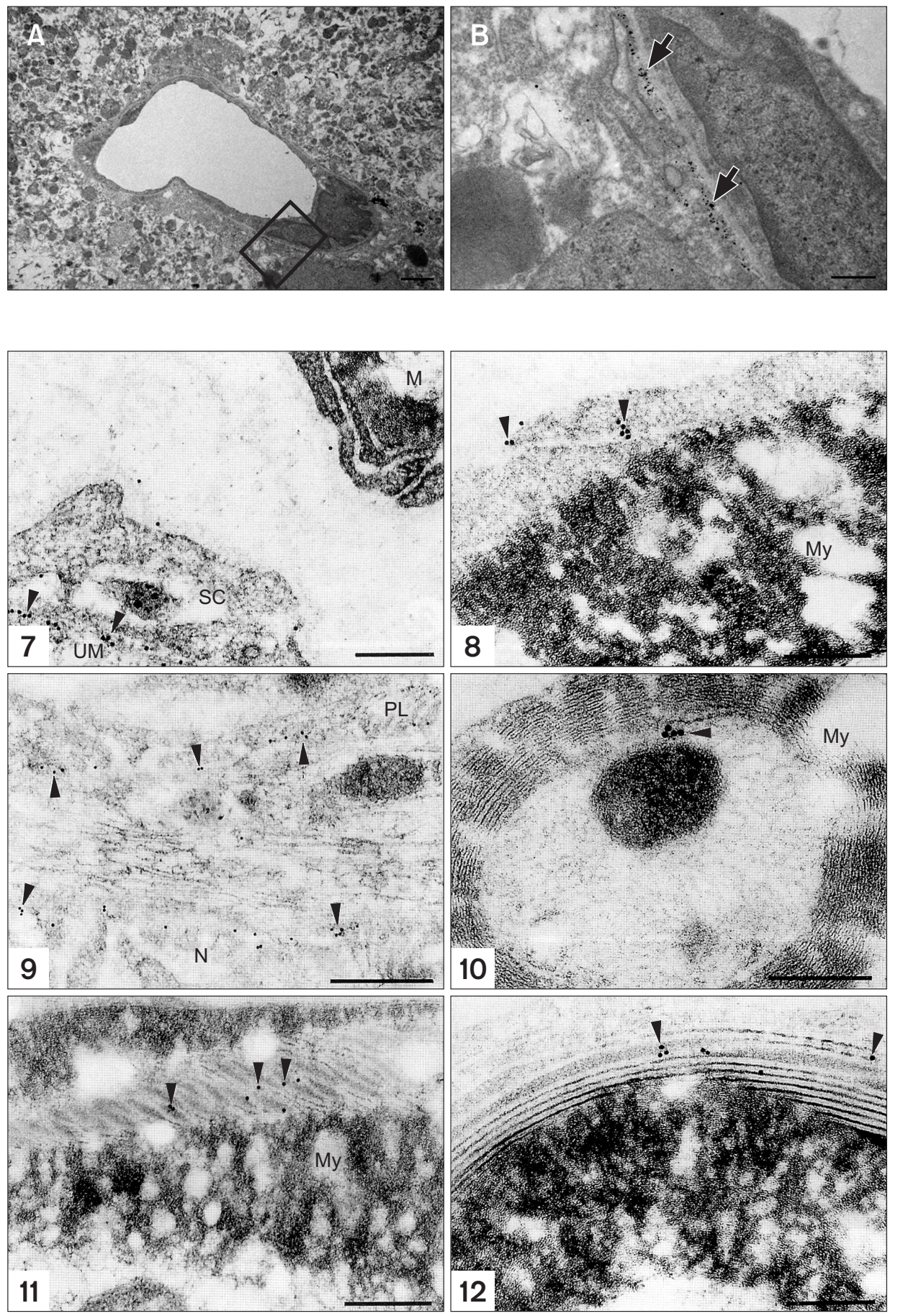

Fig. 5. (A, B) Electron micrograph showing nestin-positive cell associated with capillaries at 3 days post-ischemia by using immunogold/silver electron microscopy. Higher magnification (B) of the boxed area in Fig. 5A shows the silver grains (arrow) were exclusively localized along the bundles of intermediate filaments. Scale bars $=2 \mu \mathrm{m}$ (A), $0.4 \mu \mathrm{m}$ (B).

Fig. 6. (7) Post-embedding immunoelectron micrograph of neurofascin in 14 days old rat sciatic nerve. Unmyelinated fiber (UM) expresses neurofascin strongly in the axolemma (arrowheads), but myelinated fiber (M) doesn't express neurofascin in the axolemma at all. SC, Schwann cell cytoplasm. Scale bar=200 nm. (8) Neurofascin immunoreactive gold particles are labeled in the outer mesaxon (arrowheads). My, compact myelin sheath. Scale bar=200 nm. (9) Node (N) and paranodal loops (PL) are shown. Many neurofascin immunoreactive gold particles are localized in the nodal axolemma (arrows). Neurofascin expression was revealed in the paranodal loops as well. Scale bar $=500 \mathrm{~nm}$. (10) Post-embedding immunoelectron micrograph of neurofascin in 5 days old rat sciatic nerve. Neurofascin immunoreactive gold particles are labeled in the inner mesaxon (arrowhead). Scale bar=200 nm. (11) Post-embedding immunoelectron micrograph of neurofascin in 14 days old rat sciatic nerve. Neurofascin immunoreactive gold particles are labeled in the Schmidt-Lantermann incisures (arrowheads). Scale bar=200 nm. (12) Noncompact myelin layer which in composed of apposing Schwann cell membranes expresses neurofascin immunoreactivity (arrowheads), but compact myelin layer doesn't express neurofascin at all. Scale bar=200 nm. Adapted from the article of Chang et al. (2006) (Korean J. Electron Microsc. 36, 131-140) with original copyright holder's permission. 
30 minutes

- Primary antibody (1:200, goat anti-rabbit neurofascin) $4^{\circ} \mathrm{C}, 12$ hours

- Wash with PBS-milk-Tween 5 times

- Secondary antibody (1:50 goat anti-rabbit IgG $15 \mathrm{~nm}$ gold particle conjugated) RT, 2 hours

- Wash with PB-Tween (0.1 M PB, 0.1\% Tween 20) 5 times

- Wash with distilled water 3 times

- Fixation with $2.5 \%$ glutaraldehyde 15 minutes

- Stain with uranyl acetate, lead citrate

8. Observation (Fig. 6; Chang et al., 2006)

\section{Correlative Light and Electron Microscopy (CLEM) Using Cryo-ultramicrotome Sections}

1. Fix specimens with $4 \%$ paraformaldehyde in $0.1 \mathrm{M} \mathrm{PB}$ for 3 hours.

2. Wash in 0.1 M PB 3 times.

3. Immerse specimens in a $30 \%$ sucrose in $0.1 \mathrm{M} \mathrm{PB}$ for 3 hours, and followed by $2.3 \mathrm{M}$ sucrose in $0.1 \mathrm{M}$ PB for cryo-protection for 6 hours, placed on a shaker.

4. Cryo-sectioning into $1 \mu \mathrm{m}$ thickness using cryo-ultramicrotomy at $-100^{\circ} \mathrm{C}$, and mounting coating glass slides for immunochemistry.

5. Blocking the sections with $1 \%$ BSA in $0.01 \mathrm{M}$ PBS for 1 hour.

6. Incubate with primary antibodies in $0.01 \mathrm{M} \mathrm{PBS}$ at $4^{\circ} \mathrm{C}$ overnight.

7. Wash 3 times in $0.01 \mathrm{M}$ PBS 3 for 5 minutes each time.

8. Incubate with fluorophore-conjugated secondary antibodies in 0.01 M PBS for 3 hours at room temperature.

9. Wash in $0.01 \mathrm{M}$ PBS 3 times for 5 minutes each time and then washing in $0.1 \mathrm{M}$ PB 3 times for 5 minutes each.

10. Examine cover-slipped sections with confocal microscope and photographing at various magnifications to find specific areas by electron microscope.

11. Fix with $1 \%$ glutaraldehyde in $0.1 \mathrm{M}$ PB for 30 minutes.

12. Wash in $0.1 \mathrm{M}$ PB 3 times for 5 minutes each.

13. Fix with $1 \%$ osmium tetroxide $\left(\mathrm{OsO}_{4}\right)$ in $0.1 \mathrm{M} \mathrm{PB}$ for 10 minutes.

14. Dehydrate in a graded series of ethanol (50\%, 70\%, 80\%, $90 \%, 95 \%, 100 \% \times 3$ )

15. Embed with resin infiltration by ascending concentration of resin (ethanol/resin 2:1, 1:1, 1:2, pure resin $\times 2$ ).

16. Mount the sections on the slide glass by covering resinfilled tube.

17. Polymerize in a $60^{\circ} \mathrm{C}$ oven for 36 hours.

18. Separate tube including the section from slide glass and figure out area of interest from separated block plane.

19. Screen areas for trimming and proceed ultrathin section (80 nm thick).

20. Stain with $2 \%$ uranyl acetate for 10 minutes (Fig. 7).
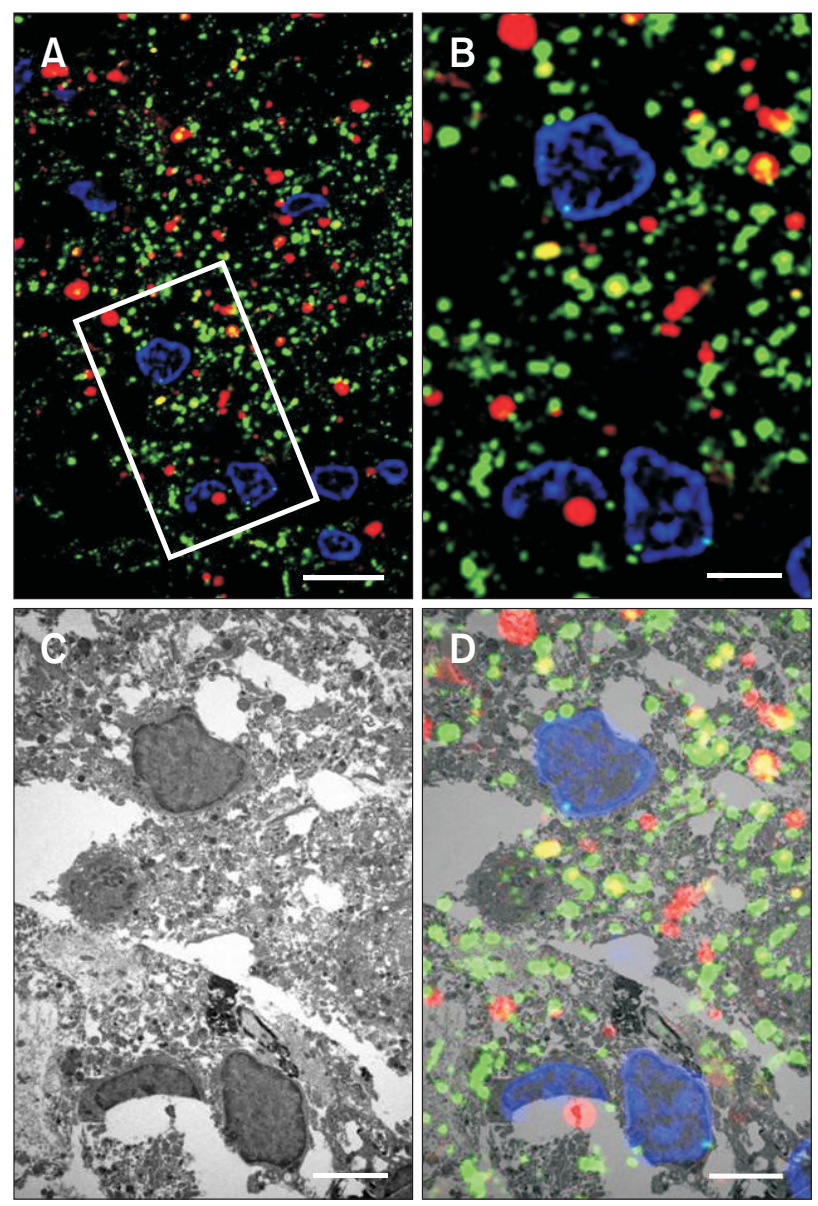

Fig. 7. (A) Confocal microscopic double-labeled image with osteopontin and mitochondria marker NDUFV2. Higher magnification the boxed area in Fig. 7A show the corresponding transmission electron microscopic image obtained from the same field in the 3-nitropropionic acid (3NP)injured lesion core (B-D). Scale bars $=5 \mu \mathrm{m}$ (A), $10 \mu \mathrm{m}$ (B-D).

\section{SUMMARY}

In this technical review, the authors introduced the immunostaining method that was actually used after introducing the antibody, main advantage of handling the antibody, mechanism of antigen-antibody reaction, principle of immunostaining and precautions.

We hope that this introduction will be helpful in the future when many researchers using electron microscopes perform immunoelectron microscopy.

\section{CONFLICT OF INTEREST}

No potential conflict of interest relevant to this article was reported. 


\section{REFERENCES}

Chang B H, You K H, Lee J H, Cho I H, Bae C S, Park C H, Han J M, Choe $\mathrm{N} \mathrm{H}$, and Chang B J (2006) A study on the localization of neurofascin in the myelinated rat sciatic nerve fibers. Korean J. Electron Microsc. 36, 131-140.

Goldberg M W (2016) High-resolution scanning electron microscopy and immuno-gold labeling of the nuclear lamina and nuclear pore com- plex. Methods Mol. Biol. 1411, 441-459.

Melo R C, Morgan E, Monahan-Earley R, Dvorak A M, and Weller P F (2014) Pre-embedding immunogold labeling to optimize protein localization at subcellular compartiments and membrane microdomains of leukocytes. Nat. Protoc. 9, 2382-2394. 